\title{
Self-management for people with inflammatory bowel disease
}

\author{
Fred Saibil MD FRCPC ${ }^{1,2}$, Emily Lai MD², Andrew Hayward MD², Jeanne Yip ${ }^{3}$, Cameron Gilbert ${ }^{4}$
}

F Saibil, E Lai, A Hayward, J Yip, C Gilbert. Self-management for people with inflammatory bowel disease. Can J Gastroenterol 2008;22(3):281-287.

\begin{abstract}
In North America and the United Kingdom, we are in the age of selfmanagement. Many patients with chronic diseases are ready to participate in the therapeutic decision-making process, and join their physicians in a co-management model. It is particularly useful to consider this concept at a time when physician shortages and waiting times are on the front page every day, with no immediate prospect of relief. Conditions such as diabetes, asthma, chronic obstructive pulmonary disease, recurrent urinary tract infections and others lend themselves to this paradigm of medical care for the informed patient. The present paper reviews some of the literature on self-management for the patient with inflammatory bowel disease (IBD), and provides a framework for the use of self-management in the IBD population, with emphasis on the concept of a patient passport, and the use of e-mail, supported by an e-mail contract, as proposed by the Canadian Medical Protective Association. Examples of specific management strategies are provided for several different IBD scenarios. Eliminating the need for some office visits has clear environmental and economical benefits. Potential negative consequences of this form of patient care are also discussed.
\end{abstract}

Key Words: Colitis; Crohn's; E-mail; Passport; Self-management

\section{L'autogestion des soins des personnes atteintes d'une maladie inflammatoire de l'intestin}

En Amérique du Nord et au Royaume-Uni, nous sommes à l'ère de l'autogestion des soins. De nombreux patients atteints d'une maladie chronique sont prêts à participer au processus de prise de décision thérapeutique et à s'allier à leur médecin dans un modèle de prise en charge conjointe. Il est particulièrement utile d'envisager ce concept en cette époque de pénurie de médecins et de temps d'attente qui font la une des journaux tous les jours, sans perspective immédiate de solution. Des maladies comme le diabète, l'asthme, la maladie pulmonaire obstructive chronique, les infections urinaires récurrentes et d'autres troubles se prêtent à ce paradigme de soins médicaux auprès du patient informé. Le présent article contient une analyse de certaines publications sur l'autogestion des soins des patients atteints d'une maladie inflammatoire de l'intestin (MII) et fournit un cadre pour utiliser cette approche auprès de la population atteinte d'une MII, en soulignant le concept de passeport des patients et le recours aux courriels appuyés par le contrat par courriel, tel qu'il est proposé par L'Association canadienne de protection médicale. Les auteurs fournissent des exemples de stratégies de prise en charge précises pour divers scénarios de MII. L'élimination de certaines consultations en cabinet a des conséquences évidentes du point de vue de l'environnement et de l'économie. On aborde également les conséquences négatives potentielles de cette forme de soins aux patients.

\section{BACKGROUND INFORMATION \\ Why self-management? \\ In North American and British medicine, we are in the age of self-management. We have moved from the traditional phase of paternalism through the phase of the educated, questioning patient to the present, in which many patients are ready to take ownership of their chronic diseases and participate in the therapeutic decision-making process.}

\section{Self-management models}

Self-management is a health care model that focuses on educating patients to monitor and manage disease symptoms, adhere to and tailor treatment regimens, and manage the impact of illness on daily functioning (1). This model has increasingly emerged as an integral aspect of patient care, largely due to the mounting burden of chronic disease, but also due to doctor shortages in some locales. As patients and their physicians grapple with illnesses that may last for decades, experience has shown that selfmanagement programs not only respond to patients' desires to be partners in their care but also allow for more effective and efficient health care delivery $(2,3)$.
Evidence from a variety of chronic diseases has shown the benefits of self-management on end points such as symptom reduction and the need for hospitalization and medical treatment. Perhaps the best reported of these is the asthma experience. Personalized action plans based on symptoms and measures such as peak expiratory flow have been widely implemented, even in the case of the pediatric population (4). A recent Cochrane review by Gibson et al (5) examined 36 trials that compared self-management education with usual care in adults with asthma. They found that selfmanagement education improved patients' quality of life, and reduced hospitalizations, emergency room visits, unscheduled visits to the doctor, days off work or school and nocturnal asthma episodes.

Self-management training is now also an integral part of the clinical management of diabetes. Common interventions include educational programs aimed at patient knowledge and understanding of disease, lifestyle behaviour modification focusing on diet and physical activity, and skill development such as self-monitoring of blood glucose and proper foot care to prevent complications. Coping skills, including relaxation and

${ }^{1}$ Division of Gastroenterology, Department of Medicine, Sunnybrook Health Sciences Centre, University of Toronto; ${ }^{2}$ Faculty of Medicine,

University of Toronto, Toronto; ${ }^{3}$ Faculty of Medicine, University of Ottawa, Ottawa, Ontario; ${ }^{4}$ Royal College of Surgeons of Ireland Medical

School, Dublin, Ireland

Correspondence and reprints: Dr Fred Saibil, H-52-2075 Bayview Avenue, Toronto, Ontario M4N 3M5. Telephone 416-480-4727,

fax 416-480-5977, e-mail fred.saibil@utoronto.ca

Received for publication September 30, 2007. Accepted October 1, 2007 
empowerment techniques, are also common aspects of education programs (6). Deakin et al (7) reviewed the evidence for group-based training for self-management strategies in people with type II diabetes mellitus. The results of this Cochrane meta-analysis demonstrated that patient education leads to improvements in fasting blood glucose levels, glycated hemoglobin and diabetes knowledge, as well as reductions in systolic blood pressure levels, body weight and the requirement for diabetes medication. Some of these effects persisted for up to two years after the education program.

Evidence also exists in favour of self-management of other chronic diseases including congestive heart failure $(8,9)$ and chronic obstructive pulmonary disease (10), as well as for recurrent acute illnesses such as recurrent urinary tract infections (11). Regier et al (12) have suggested that self-management is cost effective for long-term oral anticoagulation. Significant cost savings were demonstrated by Robinson et al (13) in their study of self-help interventions for patients with irritable bowel syndrome.

\section{Self-management for inflammatory bowel disease} Department of Health Expert Patient Programme (United Kingdom): The Department of Health for London, England provided outstanding support to the whole self-management paradigm through its establishment of the Expert Patient Programme, and the publication of the document The Expert Patient: A new approach to chronic disease management for the 21 st century (14). This city government program affirms that some patients are capable of managing their own illness in partnership with health professionals.

With this in mind, Elaine McColl and her colleagues undertook a massive study entitled "Self-Management in ulcerative colitis. A report of a randomized controlled trial with economic evaluation and qualitative assessment" (unpublished). This study has remained unpublished, at least partly because it highlights the difficulties involved in trying to demonstrate the apparent benefits of self-management.

Published studies: The United Kingdom has led the way in focusing on the self-management paradigm for people with inflammatory bowel disease (IBD). In 1999, Eaden et al (15) devised and validated a reliable questionnaire to assess patient knowledge of IBD and its treatment - the Crohn's and Colitis Knowledge Score. In 2002, Kennedy and Rogers (16), at the University of Manchester (Manchester, United Kingdom), enlisted the help of patients, general practitioners and gastroenterologists to develop a guidebook for ulcerative colitis. Their goal in doing this was to improve patient involvement in their own management. Kennedy et al (17) subsequently tested this guidebook in a controlled trial, with a view of its effects on patient knowledge, anxiety and quality of life. They concluded that the guidebook led to a sustained improvement in knowledge, without an increase in anxiety. Quality of life scores were unchanged during the study period. A more recent report by this group again highlights some of the difficulties in quantifying the value of the self-management model (18).

Kane et al (19), at the University of Chicago (Chicago, Illinois, USA), confirmed older data by showing that ulcerative colitis patients who adhere to prescribed 5-aminosalicylic acid (5-ASA) therapy are much more likely to remain in remission than those who do not adhere. Patient understanding of the goals of maintenance therapy is believed to be the key. Behaviours concerning medication compliance were further assessed in the recent paper by Hall et al (20). They concluded that a concordant approach including flexible and proactive support, as well as accurate information, is important in assisting patients with IBD to self-manage their medications effectively.

Cross and Finkelstein (21) have taken the self-management concept one step further with their study on the acceptance and feasibility of a home telemanagement system for patients with IBD. Another support technique is that of e-mail; one of the authors of this paper [FS] has been providing extensive support to self-managers in his practice through this modality.

\section{PRACTICAL INFORMATION FOR IBD PATIENTS} Definitions and strategies

One of the authors (FS) has designed several strategy models for his patients. These models provide patients with definitions for different degrees of severity of disease, with corresponding management choices. The same author has designed a simple guide to self-assessment of nutritional needs, and how to derive those needs from an enteral diet. Space does not permit full inclusion of these models here. Two examples are listed in Table 1.

\section{The patient passport}

The patient passport or patient hand-held record is a passportsized booklet or card on which a patient records the names and approximate dates of regularly scheduled tests so that he or she can remind the responsible physician or secretary to schedule tests in a timely fashion. It can also be used to record the dates and results of tests or procedures previously performed. The passport concept was initially created in a number of settings to promote patient ownership and understanding, and to improve physician implementation of focused preventive care measures (22-25).

In the United Kingdom and Australia, a maternal handheld record is used to help expectant mothers keep track of their own pregnancies and to facilitate participation in their medical care $(26,27)$. In pediatrics, the 'Road to Health' card and immunization card are both used in a number of different countries to improve child health maintenance and vaccination rates $(23,28)$.

Recently, the passport concept has been explored in the chronic disease setting with trials involving schizophrenia (29), cancer (30), stroke (31) and diabetes (32), with mixed reviews. We believe that people with IBD are likely to benefit from an IBD-focused patient passport. Drugs such as steroids, immunomodulators and biologicals require regular monitoring for complications and side effects $(33,34,35)$. Because many specialist practices are overloaded, patients with IBD - each with a unique set of issues - can help both the physician and themselves by keeping track of what tests are needed and when. A tailored IBD passport can facilitate tracking of medications, surveillance colonoscopies, past surgeries, bone mineral densitometry and, possibly, other information (Figure 1). This is not meant to replace the standard medical record or to contain every detail of every procedure but to simply provide a brief outline or summary.

Most patients can learn to use a passport, increasing the probability that optimal care will be obtained. Studies have shown that reminders from patients can improve physician compliance for preventive measures $(23,25)$. Active patient participation can improve compliance by providing a better 
TABLE 1

Two examples of self-management strategies for flares of inflammatory bowel disease

\begin{tabular}{l}
\hline Ulcerative colitis \\
\hline Mild attack (definition) \\
- Two to five trips to the toilet in $24 \mathrm{~h}$ \\
- Small amounts of blood \\
- Mild urgency \\
- Little or no need to get up from sleep \\
- Good appetite \\
- No fever \\
- Normal energy \\
Mild attack (treatment) \\
- Rectal therapies - suppositories $>$ foam > gel > liquid (ease of use) \\
- 5-ASA - start or increase oral dose \\
- Add rectal therapy \\
- 5-ASA suppositories or enemas \\
- HC foam, liquid HC or budesonide enemas \\
- Combinations (eg, 5 -ASA suppositories in the morning and HC foam at \\
bedtime) \\
- Consider budesonide (if you choose this, inform your doctor) \\
Crohn's disease \\
\hline Obstructive attack, mild (definition) \\
- Feeling 'off' \\
- Cramps \\
- May be a burst of diarrhea, then no bowel movements and no gas \\
- Nausea \\
- Mothing to eat or drink for $3 \mathrm{~h}$ to $6 \mathrm{~h}$ \\
(at least 1 cup each time), every $4 \mathrm{~h}$ to $6 \mathrm{~h}$ \\
\hline - ASA 5 -amids for $36 \mathrm{~h}$, then progress diet gradually \\
\hline
\end{tabular}

5-ASA 5-aminosalicylic acid; HC Hydrocortisone

understanding as to why certain tests are important. Studies of the maternal hand-held record have shown that patients often feel more satisfied with their care and more in control when they have their own records $(26,27)$. We believe an IBD patient passport would provide similar benefits. An example follows (Figure 1).

With patients keeping track of their own data, physicians can free up office time to focus on complicated cases. Using a passport, patients can request a booking by phone or e-mail, saving time for both themselves and the physician.

The patient passport can also be used to facilitate communication between physicians. Family physicians can obtain a general management overview, and can avoid redundant testing. Should a patient need to visit an emergency department, a passport can provide pertinent details to the emergency room staff, facilitating management.

Of course, the patient passport is not for everyone. Patients need to be highly motivated and interested in their own care for this to work. Keeping track requires a commitment to continuously update the information. A Dutch study (32), in which diabetes passports were distributed randomly in a number of hospitals revealed that only $36 \%$ of the patients in the study were still using the passport after six months.

Confidentiality is also an issue. Medical information can be exposed should the passport be lost, misplaced or stolen.

\section{Sunnybrook Health Sciences Centre}

\section{Ulcerative Colitis / Crohn's Colitis Patient Passport \\ Passport Book \#:}

Patient Name:

Date of Diagnosis:

Maximum Extent of Disease:

Medications:

\begin{tabular}{|l|l|l|l|}
\hline Drug name & Dosage & $\begin{array}{c}\text { Date } \\
\text { started }\end{array}$ & $\begin{array}{c}\text { Date and reason for D/C } \\
\text { (if applicable) }\end{array}$ \\
\hline & & & \\
\hline & & & \\
\hline & & & \\
\hline & & & \\
\hline & & & \\
\hline & & & \\
\hline & & & \\
\hline
\end{tabular}

Bone mineral densitometry:

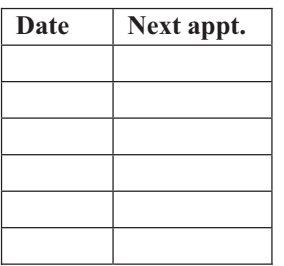

Colonoscopy:

\begin{tabular}{|l|l|}
\hline Month/Year & Next appt \\
\hline & \\
\hline & \\
\hline & \\
\hline & \\
\hline & \\
\hline & \\
\hline
\end{tabular}

Relevant GI Surgical History

\begin{tabular}{|l|l|r|}
\hline Month/Year & Surgical procedure & Hospital \\
\hline & & \\
\hline & & \\
\hline & & \\
\hline & & \\
\hline
\end{tabular}

Figure 1) An example of a tailored inflammatory bowel disease passport to facilitate tracking of medications, surveillance colonoscopies, past surgeries, bone mineral densitometry and, possibly, other information. D/C Discontinuation; GI Gastrointestinal

Storage of the information on a password-protected electronic device would likely alleviate this problem.

Finally, for the passport concept to be effective, the physician involved must be able to relinquish some responsibility of management to the patient, while being careful to avoid neglect. To solely rely on patients to remind physicians when tests are due can potentially result in patients being lost to follow-up. With the right patient attitude and education, combined with the willingness of the physician, the patient passport can be a powerful tool.

Use of e-mail and the e-mail contract

E-mail can be useful for routine matters such as laboratory results (especially if unchanged or normal), prescription information and appointment scheduling, as well as for discussion of nonurgent conditions. It has already been endorsed by patients for dealing with primary care issues such as sore throats, back pain, and cholesterol and Pap smear results (36). Also, patients can contact their physicians with nonemergent concerns, and a decision can be made about whether an appointment is warranted.

Many patients now use the Internet to keep abreast of new developments, particularly in treatment. Although detailed discussions are best dealt with in an office setting, e-mail can 
sometimes play a role in communication about advances in knowledge, especially for self-managers. A patient or family can research an area of interest and then check with the physician for advice about the relevance of the topic, and then a decision can be made about the need for an office visit.

Many IBD patients are on medications that require frequent blood work monitoring; a typical interaction is as follows: Patient: "I had a blood test today." Physician: "Your counts were fine; repeat in two weeks." Self-managers may just need a little reassurance in dealing with a minor flare. The physician may look at someone's symptoms and advise an office appointment.

Physicians also like e-mail as an option for patient communication (37). They believe that it saves them time relative to communicating by telephone, it provides better documentation and liability protection, and it allows them to deal with more patients (38). E-mails can be exchanged at the convenience of both the patient and the physician. The phone can be quick and efficient, but only if both the caller and receiver are available; unavailability of one or the other, a busy line, and lack of an automated message-taking device all waste time and effort. In one study, patients were encouraged to communicate about health issues, scheduling, prescription renewals, referrals and billing. Patients, physicians and staff had positive attitudes toward online communication, although they reported different preferences for the use of online communication based on problem complexity and sensitivity (39).

Finally, the economic benefits of incorporating e-mail into a self-management plan are unquestionable. Spending related to physician office visits can be reduced by as much as $\$ 1.92$ per patient per month, and total health care expenditure can be reduced by as much as $\$ 3.69$ per patient per month (40). In the context of a large health care system, such as the Canadian model, these per-patient savings add up. In Canada, there are approximately 190 million physician visits per year overall, costing an average of almost $\$ 40$ per visit (41). It has been estimated that online patient consultations could lead to a $20 \%$ reduction in office visits (42). This would translate to savings of approximately $\$ 1.5$ billion per year for the Canadian health care system. In addition to these savings, overall benefits to the individual patient, and to the economy in general, are foreseeable through reduction of lost productivity due to both travel time to appointments and time spent in the waiting room, as well as in the physician's office. The environment can also benefit, with elimination of the need for travel, thus keeping people out of their cars.

It is likely that much of the resistance to using e-mail communication is related to the potential legal risks. Like other modern technologies, such as fax machines, cellular phones, answering machines and voice mail, e-mail can be reproduced or redirected to unintended recipients. It is the responsibility of both the physician and the patient to ensure that these legal risks are acknowledged and properly dealt with. For physicians, the main ethical considerations that must be obeyed include patients' confidentiality, standards of practice, licensing and regulatory oversight, and informed consent (43). Other considerations include the security of the servers, the security of personal computers that may contain backup copies of e-mails and the privacy of any printed copies of this e-mail communication. Communication via an office or shared computer has additional risks; employers and online services may have a legal right to inspect and keep e-mails that pass through their systems.
Given these considerations, informed consent for the use of e-mail should be addressed at the earliest opportunity. The Canadian Medical Protective Association (CMPA) has given an opinion that it is in the best interests of both patients and their doctors to formalize this arrangement. The CMPA has provided doctors with a template document that can be used as an e-mail contract (44). In a simple but clear manner, the suggested contract outlines the possible risks that are associated with e-mail, and also clarifies the parameters of this form of interaction. The electronic relationship should not eliminate the need for office visits, but should reduce the frequency. A prospective study of a triage-based system for e-mail use in primary care found that most patients adhered to guidelines aimed at focusing content, limiting the number of requests per message and avoiding urgent requests or highly sensitive material $(45,46)$.

In the senior author's practice, at Sunnybrook Health Sciences Centre (Toronto, Ontario), e-mail is used frequently, especially for IBD patients living and working outside the city. The majority of these communications concern monitoring of blood tests related to immunosuppressives and responses to iron supplements, but other relatively common uses include advice about adjustment of steroid dosing, and fine-tuning of management regimens. In 2006, we sent out a slightly modified version of the CMPA contract, edited to suit our purposes. To date, 58 patients who had already been communicating informally with us have returned signed contracts to us. We believe that formalizing this relationship will help our patients to better understand what they can and cannot achieve via e-mail. Informal feedback has been very positive. Our version of the CMPA contract is included below (Appendix 1).

\section{Caveats and cautions}

Self-management is not for all physicians, nor all patients. There is a potential risk of the breakup of the doctor-patient 'partnership'. Doctors are trained to work alone. They are taught to assess a situation, arrive at a diagnosis as quickly as possible and make therapeutic decisions. For many physicians, this translates into a control issue. Equally bad is the situation in which the patient becomes so assertive that the doctor is marginalized, or excluded entirely, in the decision-making process. Some patients will discover that their doctors are quite uncomfortable with loss of total control, and they may resort to doubledoctoring, relying on their usual physician for the 'difficult' decisions, while consulting someone else for those situations that lend themselves to the self-management principles. Others will use 'alternative' therapies. If these are nonmedicinal, such as yoga, no harm is done. However, if patients use herbs or naturopathic treatments and do not discuss this with their gastroenterologist, they will be at risk for adverse reactions or interactions with their conventional medications. Finally, there may be a tendency to omit regularly scheduled monitoring tests, such as blood tests, colonoscopies or bone density tests, among others. Thus, patients utilizing self-management techniques should be reminded to keep in touch.

\section{CONCLUSIONS}

The self-management paradigm has potential benefits for both patients and health care practitioners. The constant challenge to attract health professionals to rural areas is compounded by the growing waiting lists in both rural and urban centres.

From the patient's point of view, there are some specific benefits. They can have a sense (or even more) of being in 
control of their lives and their disease, instead of feeling that the disease is in control. If they wish to travel, they can do so with the confidence that they can handle most situations. If they need reassurance, or expert support, they may be able to use e-mail contact with their physician, with telephone contact as a backup. If their doctor is away (travelling, hopefully!), they know that they can deal with most situations, while having a covering physician, or the local emergency room, for backup.

ACKNOWLEDGEMENTS: The authors thank $\mathrm{Mr}$ and Mrs Steven Diener for the endowment that allowed the creation of the Ilona Diener Clinical Summer Studentship in IBD at Sunnybrook Health Sciences Centre at the University of Toronto. The authors also thank Dr McColl, who provided them with a full copy of her unpublished manuscript.

The Ilona Diener Clinical Summer Students in IBD for 2004, 2005, 2006 and 2007 were Emily Lai, Andrew Hayward, Jeanne Yip and Cameron Gilbert, respectively. Emily Lai is now a resident at the University of Toronto and Dr Wayward is now a resident in Nova Scotia.

\section{APPENDIX 1 PHYSICIAN-PATIENT E-MAIL CONTRACT}

\section{Risks of using e-mail}

Dr Saibil and his staff offer patients the opportunity to communicate by e-mail. Transmitting patient information poses several risks of which you should be aware. You should not agree to communicate with Dr Saibil and his staff via e-mail without understanding and accepting these risks. The risks include, but are not limited to, the following:

- The privacy and security of e-mail communication cannot be guaranteed.

- Employers and online services may have a legal right to inspect and keep e-mails that pass through the system.

- E-mail is easier to falsify than handwritten or signed hard copies. In addition, it is impossible to verify the true identity of the sender, or to ensure that only the recipient can read the e-mail once it has been sent.

- E-mails can introduce viruses into a computer system, and potentially damage or disrupt the computer.

- E-mail can be forwarded, intercepted, circulated, stored or even changed without the knowledge or permission of Dr Saibil and his staff or you. E-mail senders can easily misaddress an e-mail, resulting in it being sent to many unintended and unknown recipients.

- E-mail is indelible. Even after the sender and recipient have deleted their copies of the e-mail, back-up copies may exist on a computer in cyberspace.

- Use of e-mail to discuss sensitive information can increase the risk of such information being disclosed to third parties.

- E-mail can be used as evidence in court

\section{Conditions of using e-mail}

Dr Saibil and his staff will use reasonable means to protect the security and confidentiality of e-mail information sent and received. However, because of the risks outlined above, Dr Saibil and his staff cannot guarantee the security and confidentiality of e-mail communication, and will not be liable for improper disclosure of confidential information that is not the direct result of intentional misconduct of Dr Saibil and his staff.

Thus, patients must consent to the use of e-mail for patient information. Consent to the use of e-mail includes your agreement with the following conditions:

- E-mails to or from you concerning diagnosis or treatment may be printed in full and made part of your medical record. Because they are part of the medical record, other individuals authorized to access the medical record, such as staff and billing personnel, will have access to those e-mails.

- Dr Saibil may forward e-mails internally to other members of his staff and to those involved, as necessary, for diagnosis, treatment, reimbursement, health care operations and other handling. Dr Saibil and his staff will not, however, forward e-mails to independent third parties without your prior written consent, except as authorized or required by law.

- Although Dr Saibil and his staff will endeavour to read and respond promptly to an e-mail from you, Dr Saibil and his staff cannot guarantee that any particular e-mail will be read and responded to within any particular period of time. Thus, you should not use e-mail for medical emergencies or other time-sensitive matters.

- E-mail communication is not an appropriate substitute for clinical examinations. You are responsible for following up on Dr Saibil's e-mail and for scheduling appointments, where warranted.

- If your e-mail requires or invites a response from Dr Saibil and his staff and you have not received a response within a reasonable time period, it is your responsibility to follow up to determine whether it was received and when he will respond.

- You should not use e-mail for communication regarding sensitive medical information, such as a diagnosis or a topic such as sexually transmitted disease, AIDS/HIV, mental health, developmental disability, or substance abuse. Similarly, Dr Saibil and his staff will not discuss such matters over e-mail.

- It is your responsibility to inform Dr Saibil and his staff of any types of information you do not want to be sent by e-mail, in addition to those set out in the bullet above. Such information that you do not want communicated over e-mail includes:

- You can add to or modify this list at any time by notifying Dr Saibil and his staff in writing.

- Dr Saibil and his staff are not responsible for information loss due to technical failures.

Instructions for communication by e-mail

To communicate by e-mail you shall:

- Limit or avoid the use of an employer's computer.

- Inform Dr Saibil and his staff of any changes in your e-mail address.

- Review the e-mail to make sure it is clear and that all relevant information is provided before sending it to Dr Saibil and his staff. 
- Take precautions to preserve the confidentiality of e-mails, such as using screen savers and safeguarding computer passwords.

- Withdraw consent only by e-mail or written communication to Dr Saibil and his staff.

- Should you require immediate assistance, or if your condition appears serious or rapidly worsens, you should not rely on e-mail. Rather, you should call Dr Saibil's office for consultation or an appointment, visit Dr Saibil's office or take other measures, as appropriate.

\section{Patient acknowledgement and agreement}

I acknowledge that I have read and fully understand this consent form. I understand the risks associated with the communication of e-mail between Dr Saibil and his staff and me, and consent to the conditions outlined herein, as well as any other instructions that Dr Saibil and his staff may impose to communicate with patients by e-mail. I acknowledge Dr Saibil's and his staff's right to, upon the provision of written notice, withdraw the option of communicating through e-mail. Any questions I may have had were answered.

Patient name

Patient e-mail

Patient address

Patient signature

Date

Witness signature

Date

anxiety and quality of life. Health Soc Care Community 2003;11:64-72

18. Richardson G, Sculpher M, Kennedy A, et al. Is self-care a cost-effective use of resources? Evidence from a randomized trial in inflammatory bowel disease. J Health Serv Res Policy 2006;11:225-30.

19. Kane S, Huo D, Aikens J, Hanauer S. Medication nonadherence and the outcomes of patients with quiescent ulcerative colitis. Am J Med 2003;114:39-43.

20. Hall NJ, Rubin GP, Hungin AP, Dougall A. Medication beliefs among patients with inflammatory bowel disease who report low quality of life: A qualitative study. BMC Gastroenterol 2007;7:20.

21. Cross RK, Finkelstein J. Feasibility and acceptance of a home telemanagement system in patients with inflammatory bowel disease: A 6-month pilot study. Dig Dis Sci 2007;52:357-64.

22. Dickey LL. Promoting preventive care with patient-held minirecords: A review. Patient Educ Couns 1993;20:37-47.

23. McCormick MC, Shapiro S, Starfield BH. The association of patient-held records and completion of immunizations. Clin Pediatr (Phila) 1981;20:270-4.

24. Dickey LL, Petitti D. A patient-held minirecord to promote adult preventive care. J Fam Pract 1992;34:457-63.

25. Turner RC, Waivers LE, O'Brien K. The effect of patient-carried reminder cards on the performance of health maintenance measures. Arch Intern Med 1990;150:645-7.

26. Homer CS, Davis GK, Everitt LS. The introduction of a womanheld record into a hospital antenatal clinic: The bring your own records study. Aust N Z J Obstet Gynaecol 1999;39:54-7.

27. Brown HC, Smith HJ. Giving women their own case notes to carry during pregnancy. Cochrane Database Syst Rev 2004:CD002856.

28. Crisp NG, Donald PR. The 'Road to Health' card and immunisation records. S Afr Med J 1987;72:331-3.

29. Lester H, Allan T, Wilson S, Jowett S, Roberts L. A cluster randomised controlled trial of patient-held medical records for people with schizophrenia receiving shared care. Br J Gen Pract 2003;53:197-203.

30. Lecouturier J, Crack L, Mannix K, Hall RH, Bond S. Evaluation of a patient-held record for patients with cancer. Eur J Cancer Care (Engl) 2002;11:114-21.

31. Ayana M, Pound P, Lampe F, Ebrahim S. Improving stroke patients' care: A patient held record is not enough. BMC Health Serv Res 2001;1:1.

32. Dijkstra RF, Braspenning JC, Huijsmans Z, et al. Introduction of diabetes passports involving both patients and professionals to improve hospital outpatient diabetes care. Diabetes Res Clin Pract 2005;68:126-34

33. Carter MJ, Lobo AJ, Travis SP, for the IBD Section, British Society of Gastroenterology. Guidelines for the management of inflammatory bowel disease in adults. Gut 2004;53(Suppl 5):V1-16.

34. Hanauer SB, Sandborn W, for the Practice Parameters Committee of the Amercian College of Gastroenterology. Management of Crohn's disease in adults. Am J Gastroenterol 2001;96:635-43. 
35. Kornbluth A, Sachar DB. Ulcerative colitis practice guidelines in adults (update): American College of Gastroenterology, Practice Parameters Committee. Am J Gastroenterol 2004;99:1371-85

36. Car J, Sheikh A. Email consultations in health care: 1 - scope and effectiveness. BMJ 2004;329:435-8.

37. Slack WV. A 67-year-old man who e-mails his physician. JAMA 2004;292:2255-61. (Erratum in 2005;293:425).

38. American College of Physicians. The Changing Face of Ambulatory Medicine - Reimbursing Physicians for ComputerBased Care: ACP Analysis and Recommendations to Assure Fair Reimbursement for Physician Care Rendered online. Philadelphia: American College of Physicians, 2003: Policy Paper.

39. Katz SJ, Nissan N, Moyer CA. Crossing the digital divide: Evaluating online communication between patients and their providers. Am J Manag Care 2004;10:593-8.

40. RelayHealth. The RelayHealth webVisit Study. Final report. January 2003
41. Public Health Agency of Canada. Report 3: Exploring the Link Between Work-Life Conflict and Demands on Canada's Health Care System. March 2004

42. PriceWaterhouseCoopers. HealthCast 2010: Smaller World, Bigger Expectations. 1999.

43. Spielberg AR. On call and online: Sociohistorical, legal, and ethical implications of e-mail for the patient-physician relationship. JAMA 1998;280:1353-9.

44. Ceresia P, Crolla DA. Physician-patient e-mail communication: Legal risks. The Canadian Medical Protective Association Information Sheet. December 2003.

45. White CB, Moyer CA, Stern DT, Katz SJ. A content analysis of e-mail communication between patients and their providers: Patients get the message. J Am Med Inform Assoc 2004;11:260-7.

46. Katz SJ, Moyer CA, Cox DT, Stern DT. Effect of a triage-based Email system on clinic resource use and patient and physician satisfaction in primary care: A randomized controlled trial. J Gen Intern Med 2003;18:736-44. 


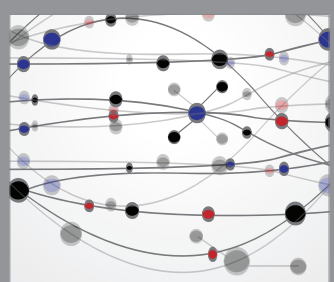

The Scientific World Journal
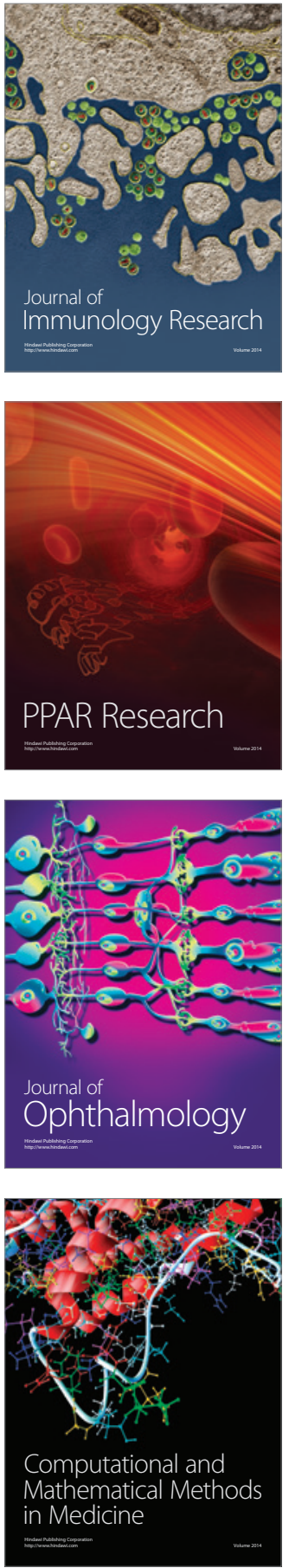

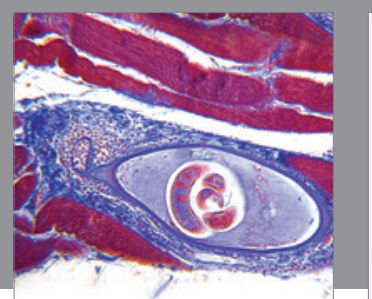

Gastroenterology Research and Practice

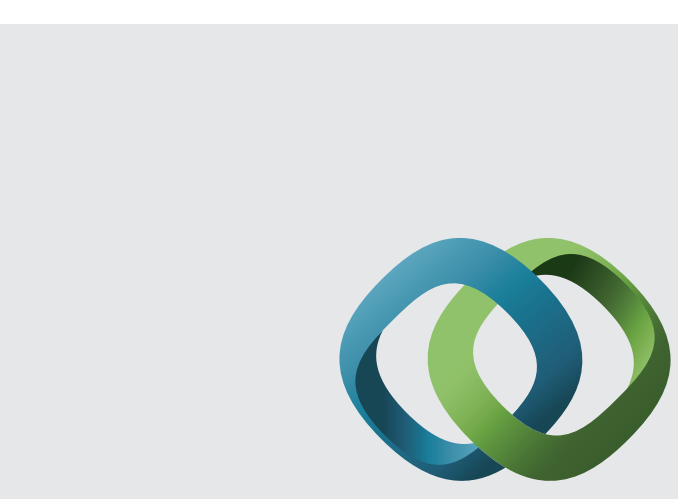

\section{Hindawi}

Submit your manuscripts at

http://www.hindawi.com
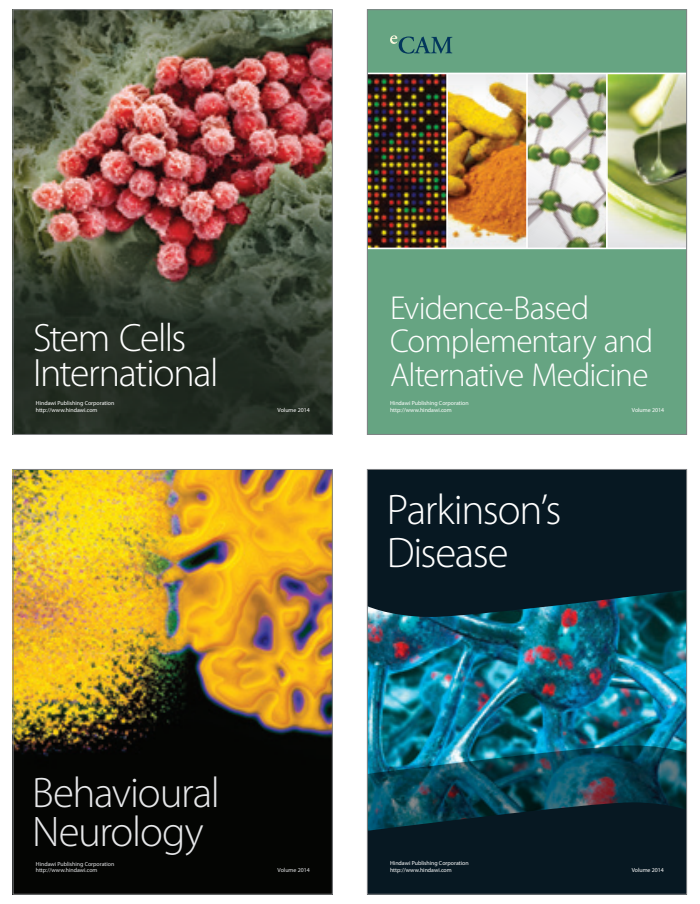
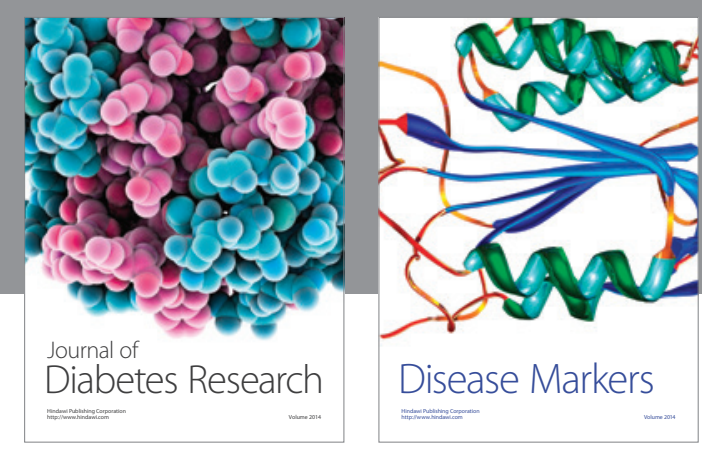

Disease Markers
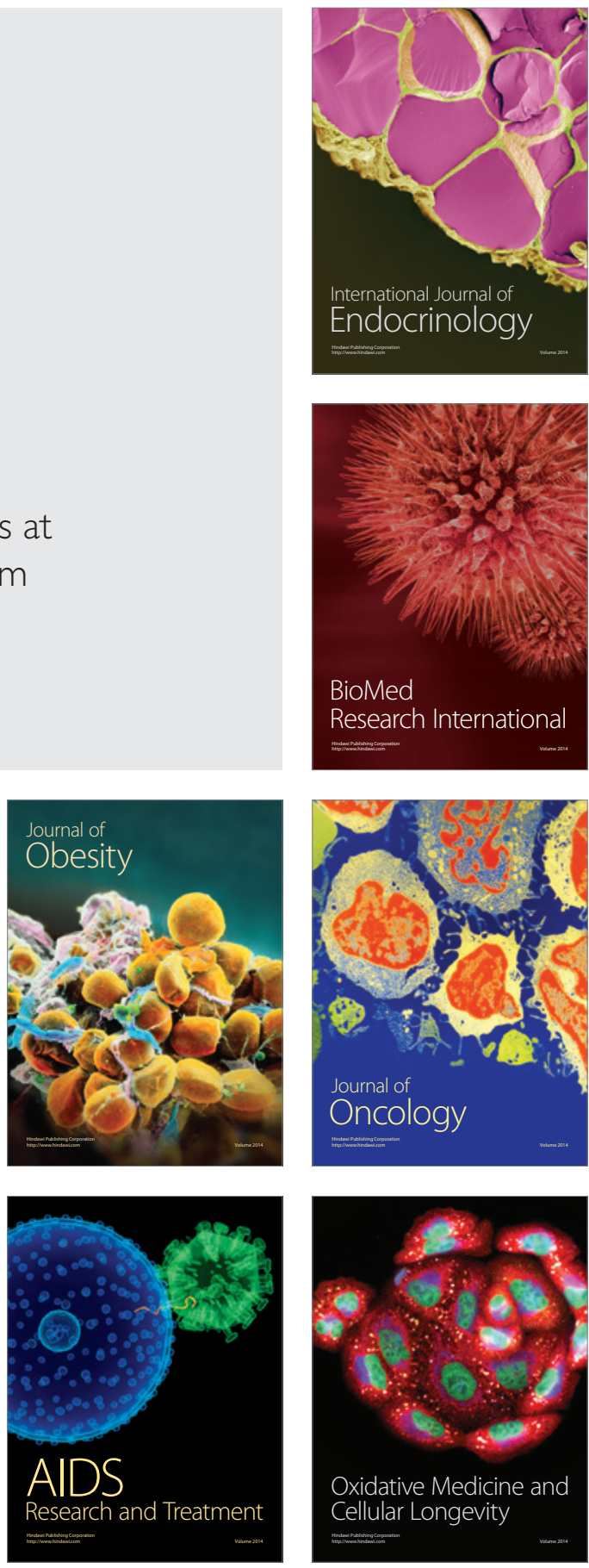